\title{
Patients receiving opioid maintenance treatment in primary care: successful chronic hepatitis $C$ care in a real world setting
}

\author{
André Seidenberg ${ }^{1,2}$, Thomas Rosemann ${ }^{1}$ and Oliver Senn ${ }^{1 *}$
}

\begin{abstract}
Background: Injection drug users (IDUs) represent a significant proportion of patients with chronic hepatitis C $(\mathrm{CHC})$. The low treatment uptake among these patients results in a low treatment effectiveness and a limited public health impact. We hypothesised that a general practitioner (GP) providing an opioid maintenance treatment (OMT) for addicted patients can achieve CHC treatment and sustained virological response rates (SVR) comparable to patients without drug dependency.
\end{abstract}

Methods: Retrospective patient record analysis of $85 \mathrm{CHC}$ patients who received OMT for more than 3 months in a single-handed general practice in Zurich from January 1, 2002 through May 31, 2008. CHC treatment was based on a combination with pegylated interferon and ribavirin. Treatment uptake and SVR (undetectable HCV RNA 6 months after end of treatment) were assessed. The association between treatment uptake and patient characteristics was investigated by multiple logistic regression.

Results: In 35 out of 85 CHC patients (52 males) with a median (IQR) age of 38.8 (35.0-44.4) years, antiviral therapy was started (41.2\%). Median duration (IQR) of OMT in the treatment group was 55.0 (35.0-110.1) months compared to the group without therapy $24.0(9.8-46.3)$ months $(p<0.001)$. OMT duration remained a significant determinant for treatment uptake when controlled for potential confounding. SVR was achieved in 25 out of 35 patients (71\%).

Conclusion: In addicted patients a high CHC treatment and viral eradication rate in a primary care setting in Switzerland is feasible. Opioid substitution seems a beneficial framework for CHC care in this "difficult to treat" population.

Keywords: Hepatitis C, Methadone substitution, Primary care

\section{Background}

Chronic hepatitis $\mathrm{C}$ infection (CHC) is a major cause of end-stage liver disease (ESLD). Injection drug users (IDUs) are a major risk group for HCV infection [1] thus they significantly contribute to the patient group with ESLD in the future [2]. In recent years treatment efficacy of $\mathrm{CHC}$ has been steadily increased and a successful virus eradication can be achieved in up to $80 \%$ of patients with genotype 2 and 3 and in about $50 \%$ of patients chronically infected with genotype 1 [3-5]. However data suggest that about $70 \%$ of patients with

\footnotetext{
*Correspondence: oliver.senn@usz.ch

'Institute of General Practice and Health Services Research, University of Zurich, Zurich, Switzerland

Full list of author information is available at the end of the article
}

confirmed $\mathrm{CHC}$ go untreated [6-8] therefore reducing therapeutic effectiveness of an anti-HCV therapy.

Increasing evidence suggests similar treatment efficacy of a pegylated interferon-based (pegIFN) combination therapy with ribavirin on $\mathrm{HCV}$ clearance in patients with substance abuse compared to patients without drug dependency [9-13]. Despite the revised NIH consensus on medical management of $\mathrm{HCV}$ infection that recommended a treatment decision on an individual basis [14] current clinical practice suggests that $\mathrm{CHC}$ patients with a history of IDU have a lower chance of getting antiviral therapy compared to other patient groups $[7,15]$. This further emphasize that the true therapeutic impact of an anti-CHC therapy is rather an issue of access to treatment than of drug efficacy.

\section{Biomed Central}


In IDUs concomitant illicit drug use, problem drinking, comorbid medical (e.g. HIV) and psychiatric conditions are prevalent representing common barriers to antiviral treatment. On the other hand opioid maintenance treatment (OMT) is established in the therapy of substance abuse [16] and has been shown to be an effective framework for adherence and virological success in HIV treatment $[17,18]$. In addition we previously demonstrated the beneficial role of a substitution treatment as a therapeutic framework for a successful CHC case finding [19]. We hypothesized that a general practitioner (GP) providing an integrated chronic care approach including an OMT can achieve similar $\mathrm{CHC}$ treatment rates and viral eradication rates compared to patients without drug dependency. In addition we aimed to assess patient characteristics including duration of OMT which were associated with $\mathrm{CHC}$ treatment initiation in a primary care setting.

\section{Methods}

\section{Patients and setting}

Retrospective records review of patients receiving opioid maintenance treatment (OMT) in the study period between January 1, 2002 through May 31, 2008. A detailed description of the study population and the setting has been previously reported elsewhere [19]. Briefly, all patients $\geq 18$ years old and participating for at least 3 months in an official office-based OMT programme run by a single-handed general practice located in Zurich, Switzerland were eligible for $\mathrm{CHC}$ assessment and evaluation for antiviral therapy in the case of a $\mathrm{CHC}$ infection. In 327 out of 360 patients (90.8\%) on OMT a successful $\mathrm{CHC}$ assessment could be performed and 85 out of the 327 patients (26\%) were chronically infected with hepatitis C. The OMT regimen (methadone, buprenorphine or morphine) was based on a computer-assisted drug prescription and delivery system (CDDD) that provides a patient tailored dosage regime within a safety framework allowing the patients to choose dosage within an individualised maximal daily dose [20]. The diagnosis of chronic hepatitis $\mathrm{C}$ was based on a detectable HCV RNA concentration and a reported HCV genotype performed by an approved laboratory using a quantitative polymerase-chain reaction. All patients had not been treated previously for $\mathrm{CHC}$. The practice staff has long experience and is specifically trained in OMT and HCV care. All HCV treatments were given in the general practice coordinated and supervised by the GP. A close collaboration within a network of hepatologists, infectiologists and psychiatrists guaranteed rapid access to spezialized care within less than three days. Prior to the OMT and HCV screening patients were asked for their informed consent in an anonymous data analysis. Under Swiss ethics guidelines the study did not require a formal ethics approval.

\section{Treatment protocol}

In all $85 \mathrm{CHC}$ patients risks and opportunities of a specific antiviral therapy have been discussed. Patients infected with HCV genotypes 1 and 4 were treated with once-weekly injections of peginterferon alfa-2a $(180 \mu \mathrm{g})$, plus ribavirin (1000 mg or $1200 \mathrm{mg} /$ day by weight in divided dose) for 48 weeks. A treatment regimen of ribavirin $800 \mathrm{mg} /$ day (divided in two doses) and peginterferon alfa-2a $180 \mu \mathrm{g} /$ week subcutaneously for 24 weeks was used for patients with HCV genotype 3 (no patient of the current study population was infected with genotype 2). Peginterferon injections were applied by the medical staff of the general practice mostly while patients received their substitution treatment. Direct dose adjustments according to current treatment guidelines were possible as laboratory point-of care testing (differential blood count) was available at the general practice. Ribavirin has been distributed on a weekly basis in patients with good compliance and a daytime structure (e.g. certificate of employment) or on a daily observed treatment regimen. Viremia was measured at week 12, at the end of treatment, and 6 months after the end of treatment.

Prior to antiviral treatment start patients with poorly controlled psychiatric disorders were stabilized by pharmacological therapies. A prophylactic treatment was started in patients with a history of depressive disorder before beginning an antiviral therapy. Patients were systematically counselled for a reliable contraception and in women a hormone-releasing intrauterine device $\left(\right.$ Mirena $^{\mathrm{TM}}{ }^{\mathrm{M}}$ ) was routinely recommended. Substance abuse including injection drug use was not an exclusion criteria for an interferonbased therapy, however abstinence (or at least a substantial reduction) of alcohol and concomitant substance abuse was strongly recommended in all patients.

\section{Outcome measures and assessments}

Treatment rate and treatment success were primary outcomes and defined as follow: The proportion of evaluated $\mathrm{CHC}$ patients who started an interferon-based therapy and the proportion of treated patients with a sustained virologic response (SVR) (i.e. undetectable HCV RNA in the serum 6 months after end of treatment). Viral eradication rate at the end of treatment (ETR) and SVR according to genotypes and in HIV-coinfected patients were secondary outcomes.

OMT-related data (i.e. duration, average dose) could be accessed and further processed from CDDD (see above). Demographics, psychiatric co-morbidities (based on clinical grounds), self-declared addiction-specific variables (i.e. history of IDU and current IDU, concomitant problematic drug and alcohol abuse), and socialand occupational characteristics (i.e. housing situation, employability expressed as a percentage of a full time aequivalent based on a certificate of employment) were 
assessed by systematic charts review. Problematic substance misuse including alcohol was defined on consensus within the practice team based on clinical observation and patients' self-reports during routine daily or weekly OMT provision. Substance users' self-reports have been shown to be reliable, especially in OMT programmes that assure confidentiality and absence of adverse consequences [21]. Patients suffering from a severe adverse event related to a psychiatric co-morbidity (e.g. suicidal behaviour, psychiatric hospitalisation) were considered as unstable.

\section{Statistical analysis}

Descriptive statistics were calculated for all variables. Patients were categorized according to their history of $\mathrm{CHC}$ treatment (i.e. "treatment start" vs. "no $\mathrm{CHC}$ treatment"). Non-parametric group comparisons were performed to test for differences in distributions of patient characteristics. A multiple logistic regression was used to further assess the independent associations between $\mathrm{CHC}$ treatment history and patient characteristics. All statistical analysis were performed using STATA for Windows (version 10.1; Stata Corp., College Station, Texas).

\section{Results}

Baseline characteristics of the 85 patients receiving OMT with a concomitant diagnosis of chronic hepatitis C $(\mathrm{CHC})$ are described in Table 1. Patients started substance abuse on average at the age (IQR) of 18.6 (15.6-20.7) years. Median (IQR) age and age entering the current OMT programme was 38.8 (35.0-44.4) and 34.0 (30.2-39.6) years, respectively. A vast majority of the patients $(90.6 \%)$ was on methadone maintenance treatment and 11 patients (12.9\%) experienced more than 1 opiate for long-term substitution. The median (IQR) duration on OMT was 37.1 (14.5-72) months with a wide range between 4 to 310.9 months. During the study period median prescription for methadone, buprenorphine and morphine was 72.8 (50.1-119.8), 6.2 (3.0-6.5), and 430.5 (312.1-514.8) milligram, respectively. Psychiatric comorbidity was high with about $40 \%$ suffering from an unstable disorder and almost one third having a stable condition with or without treatment. The majority of the patients (70.3\%) suffering from an unstable psychiatric disorder could have been referred for a psychiatric treatment. All of the referred patients have been diagnosed with a mood disorder and the majority $(80.8 \%)$ of them suffered from a psychiatric comorbide personality disorder. Former injection drug use (IDU) was reported in the vast majority of the patients and almost 20\% reported current IDU. Problematic drug abuse or excessive alcohol consumption was present in almost one third of the patients. Most of the patients had a permanent residence with part- or fulltime employment. HIV-co-infection prevalence was $20 \%$.

\section{CHC treatment rate and patient determinants for treatment decision}

In 35 patients out of the $85 \mathrm{CHC}$ patients an antiviral treatment with pegylated interferon and ribavirin was started, corresponding to a treatment rate of $41.2 \%$. Group comparisons between patients who started a therapy and patients who disagreed to a HCV treatment are presented in Table 2. Duration of OMT was significantly longer in patients who started an antiviral therapy. This association remained statistically significant and revealed an odds ratio $(95 \%$ CI) of $1.020(1.006-1.04) \quad(p=0.01)$ when controlling for potential confounders in a multiple logistic regression. There was no evidence of a non-linear

Table 1 Characteristics of CHC patients $>3$ months on opioid maintenance treatment (OMT)

\begin{tabular}{|c|c|}
\hline Demographics & $\begin{array}{l}\%(n)^{*} \text { or median } \\
{\left[\text { IQRR }(n)^{*}\right.}\end{array}$ \\
\hline Male & $61.2(52)$ \\
\hline Age (years) & $38.8(35.0-44.4)$ \\
\hline \multicolumn{2}{|l|}{ Opioid maintenance therapy (OMT): } \\
\hline Age beginning substance abuse (years) & $18.3(15.6-20.7)$ \\
\hline Age beginning the current OMT (years) & $34.0(30.2-39.6)$ \\
\hline Methadone as last OMT medication & $90.6(77)$ \\
\hline Buprenorphin as last OMT medication & $4.7[4]$ \\
\hline Morphin as last OMT medication & $4.7[4]$ \\
\hline Use of $\geq 1$ different opioid in the past & $12.9[11]$ \\
\hline Duration of OMT (months) & $37.1(14.5-72)$ \\
\hline Average methadone dose during OMT (mg) & $72.8(50.1-119.8)$ \\
\hline \multicolumn{2}{|l|}{ Psychiatric comorbidity: } \\
\hline No psychiatric disorder & $28.2[24]$ \\
\hline Stable disorder without treatment & $12.9[11]$ \\
\hline Stable disorder under treatment & $15.3[13]$ \\
\hline Unstable disorder & $43.5(37)$ \\
\hline \multicolumn{2}{|l|}{ Injection drug use (IDU): } \\
\hline In the past & $92.9(79)$ \\
\hline Current & $17.7[15]$ \\
\hline \multicolumn{2}{|l|}{ Other drug and excessive alcohol use: } \\
\hline Heroin & $27.1[23]$ \\
\hline Cocaine & $25.9[22]$ \\
\hline Benzodiazepines & $20.2[17]$ \\
\hline Alcohol & $31.8[27]$ \\
\hline \multicolumn{2}{|l|}{ Occupational and housing variables: } \\
\hline Employability (\%) & $60(30-100)$ \\
\hline Single household & $54.1(46)$ \\
\hline Shared household & $36.5(31)$ \\
\hline Other lodging \# & $9.4[8]$ \\
\hline \multicolumn{2}{|l|}{ HIV-co-infection } \\
\hline HIV positive & $20[16]^{*}$ \\
\hline
\end{tabular}

*Total number of patients= 85; HIV status was missing in 5 patients; ${ }^{*}$ lodging of patients without stable housing was as follows: homeless [2], asylum [2], social institutions [2], accommodation by friends [2]. 
Table 2 Determinants of CHC treatment decision in CHC patients $>3$ months on OMT

\begin{tabular}{|c|c|c|c|}
\hline \multirow[t]{2}{*}{ Determinants } & \multirow{2}{*}{$\frac{\text { Treatment start }(\mathrm{n}=35)}{\%(\mathrm{n}) \text { or median }[\mathrm{IQR}]}$} & \multirow{2}{*}{$\frac{\text { No CHC treatment }(n=50)}{\%(n) \text { or median }[I Q R]}$} & \multirow[t]{2}{*}{ P-value* } \\
\hline & & & \\
\hline \multicolumn{4}{|l|}{ Demographics: } \\
\hline Male & $65.7[23]$ & $58[29]$ & \\
\hline Female & $34.3[12]$ & $42[21]$ & 0.48 \\
\hline Age (years) & $41.8(37.2-45.1)$ & $37.5(34.8-43.8)$ & 0.06 \\
\hline Age beginning OMT (years) & $35.0(31.9-39.9)$ & $33.4(29.2-39.1)$ & 0.45 \\
\hline \multicolumn{4}{|l|}{ Opiate maintenance therapy: } \\
\hline Methadone & $88.5(31)$ & $92(46)$ & \\
\hline Buprenorphin & $8.6[3]$ & $2[1]$ & \\
\hline Morphin & $2.9[1]$ & $6[3]$ & 0.51 \\
\hline Single OMT therapy & $88.6(31)$ & $86(43)$ & \\
\hline Use of $\geq 1$ different opiate in the past & $11.4[4]$ & $14[7]$ & 1.0 \\
\hline Duration of OMT (months) & $55.0(35.0-110.1)$ & $24.0(9.8-46.3)$ & $<0.001^{\#}$ \\
\hline Average methadone dose during OMT (mg) & $73(50-120)$ & $73(50-122)$ & 0.83 \\
\hline \multicolumn{4}{|l|}{ Psychiatric comorbidity: } \\
\hline None or stable disorder & $68.6[24]$ & $52[24]$ & \\
\hline Unstable disorder & $31.4[11]$ & $48[26]$ & 0.060 \\
\hline \multicolumn{4}{|l|}{ Injection drug use (IDU): } \\
\hline In the past, yes & $91(32)$ & $94(47)$ & \\
\hline In the past, no & $9[3]$ & $6[3]$ & 0.69 \\
\hline Current, yes & $8.6[3]$ & $24[12]$ & \\
\hline Current, no & $91.4(32)$ & $76(38)$ & 0.086 \\
\hline \multicolumn{4}{|l|}{ Other drug and excessive alcohol use: } \\
\hline Current heroin use & $20[7]$ & $32[16]$ & \\
\hline No heroin use & $80[28]$ & $68(34)$ & 0.22 \\
\hline Current cocaine use & $25.7[9]$ & $26[13]$ & \\
\hline No cocaine use & $74.3[26]$ & $74(37)$ & 0.98 \\
\hline Current benzodiazepine use & $14.7[5]$ & $26[12]$ & \\
\hline No benzodiazepine use & $85.3[29]$ & $74(38)$ & 0.41 \\
\hline Excessive alcohol use & $28.6[10]$ & $34[17]$ & \\
\hline No alcohol excess & $71.4[25]$ & $66(33)$ & 0.60 \\
\hline \multicolumn{4}{|l|}{ Occupational and housing variables: } \\
\hline Employability (\%) & $60(30-100)$ & $60(30-100)$ & 0.52 \\
\hline Single household & $40[14]$ & $34[17]$ & \\
\hline Shared household & $51.4[18]$ & $56[28]$ & \\
\hline Other lodging & $8.6[3]$ & $10[5]$ & 0.90 \\
\hline \multicolumn{4}{|l|}{ HIV-co-infection $^{\dagger}$} \\
\hline HIV positive & $14.7[5]$ & 23.9 [11] & \\
\hline HIV negative & 85.3 [29] & $76.1(35)$ & 0.40 \\
\hline
\end{tabular}

*Group comparisons by Chi-square or Fisher exact as appropriate and Mann-Whitney test:

\# remained independently associated with treatment start after controlling for age, sex, psychiatric comorbidity, IDU, drug and alcohol use, employability, housing and HIV-co-infection with an OR $(95 \% \mathrm{Cl})$ of $1.02(1.006-1.04)(\mathrm{p}=0.01)$; ${ }^{\dagger} \mathrm{HIV}$-status was missing in 5 patients.

relationship between OMT duration and treatment uptake. The most frequent reason against $\mathrm{CHC}$ treatment was patient refusal in 40 cases $(80 \%)$. No treatment was performed due to various somatic reasons in the remaining 10 patients (20\%).

\section{CHC treatment success}

In 25 out of 35 patients who started a $\mathrm{CHC}$ treatment no HCV-RNA could be detected 6 months after the end of treatment corresponding to a sustained virological response rate (SVR) of $71 \%$. Three patients with successful 
HCV-clearance after initial treatment suffered from a relapse, corresponding to a success rate at the end of treatment of $80 \%$ (28/35). When stratified according to HCV genotypes SVR was $76 . \%$ in genotype 3 (10 out of 13 patients), $73.7 \%$ in genotype 1 (14 out of 19 patients), and $33.3 \%$ in genotype 4 ( 1 out of 3 patients). In 3 out of the 5 HIV-co-infected patients a SVR could be achieved.

Reasons for a failure of pegIFN+RBV in the 10 patients starting an antiviral therapy were as follow: non-responder $(n=6)$, relapse $(n=3)$, early treatment stop due to medical reasons $(n=1)$.

\section{Discussion}

This study examined $\mathrm{CHC}$ treatment and success rates in unselected patients appearing "difficult to treat" in a single-handed general practice in Switzerland. Although a substantial proportion of the study population suffered from psychiatric comorbidities, reported excessive alcohol consumption and current drug misuse including injection drug use, treatment could be started in $41.2 \%$ and resulted in an overall sustained virological response rate of $71 \%$. The duration of OMT was associated independently and positively with the start of a $\mathrm{CHC}$ treatment.

The observed treatment rate compares favourably with previous studies although comparisons have to be interpreted with caution as patient populations differ greatly across studies. In a UK population of $\mathrm{CHC}$ patients, Irving et al. [22] reported an overall treatment rate of $10.2 \%$ with a wide range varying according to the source of original $\mathrm{HCV}$ screening test with the highest rate of $21.4 \%$ in patients referred from GPs and a treatment rate of only $1.6 \%$ in patients originally screened for HCV by specialist units for drug and alcohol. Butt and colleagues [23] found a treatment rate of $11.8 \%$ in unselected veterans who were older (median age 50 years) compared to our study sample but comparable with regard to the prevalence of comorbidities such as psychiatric disorders and drug and alcohol dependence. The cumulative chance of starting $\mathrm{CHC}$ treatment in a 5 year period has been estimated to $33 \%$ in a representative Danish $\mathrm{CHC}$ cohort study [24]. Among patients attending the specialist consultations of the Swiss Hepatitis C Cohort Study (SDDS) [25] a history of $\mathrm{CHC}$ related treatment has been reported in $31 \%$ of the whole cohort and in $51 \%$ in the subgroup of cirrhotics. We found an independent and positive association between treatment initiation and the duration of OMT. Thus a patient spending 37 months (i.e. the median duration of OMT in our study population) on opioid substitution has doubled the chance ( i.e. OR $1.02^{37 \text { months }}=2.0$ ) of getting started $\mathrm{CHC}$ treatment compared to a patient simply fulfilling the inclusion criteria of minimum 3 months on substitution. This beneficial effect of OMT has already been shown to increase adherence and virological success in HIV treatment $[16,18]$ and is in line with the finding that an ongoing OMT significantly increased the chance of a successful $\mathrm{CHC}$ case finding [19]. We are not aware of a study that has assessed the specific role of an OMT programme in the context of $\mathrm{CHC}$ treatment initiation. Our results further strengthened OMT as a favourable therapeutic setting, expanding its role for HCV-related care.

We achieved a viral eradication rate similar compared to randomized controlled efficacy trials reporting a sustained virological response up to $80 \%$ of patients with genotype 2 and 3 and in about $50 \%$ of patients chronically infected with genotype 1 [3-5]. The selection criteria for the aforementioned multicenter registration trials however excluded IDUs thus although internal validity of these studies is high illicit drug users constitute the largest proportion of $\mathrm{CHC}$ patients and the results do not represent treatment effectiveness in a "real world setting". Our response rate is in line with a recent metaanalysis suggesting similar treatment efficacy of an antiviral therapy on $\mathrm{HCV}$ clearance in patients receiving OMT compared to patients without drug dependency [9]. However in only 3 out of the 16 studies included in the aforementioned meta-analysis active ongoing illicit drug use was not an exclusion criteria thus our results provided further evidence that successful viral eradication is feasible in a population normally excluded from clinical trials and judged "difficult to treat".

We are aware that the analysis of our study does not address the $\mathrm{CHC}$ treatment effectiveness of a primary care setting in comparison to a specialized medical care setting due to the lack of a randomised controlled intervention. The current standard of care for the treatment of chronic $\mathrm{HCV}$ infection which is also recommended for patients with substance abuse was applied by the attending GP with a high level of commitment and a special interest in addiction medicine. Providing chronic care (i.e. substitution, psychiatric comorbidities) in combination with acute somatic care is a main feature of a primary care setting. Our treatment rate is in line with a recent randomized controlled study evaluating the impact of an integrated care approach among $\mathrm{CHC}$ patients originally deferred from $\mathrm{CHC}$ therapy due to mental health and substance abuse comorbidities [26]. In this study patients receiving an integrated care intervention reached a treatment eligibility of $42 \%$ compared to the standard care group with a significant lower eligibility rate of $18 \%$. In our population the level of homelessness and unemployment was relatively low but similar when compared to GP patients in other OMT programmes in Switzerland, which probably reflects the low-threshold management of drug addicts in Switzerland [27]. Furthermore it is important to note that an OMT durationof fewer than 3 months was an exclusion criteria thus a selection of our population probably related to a high level 
of integration in the social framework has to be considered when compared to other settings.

From a clinical perspective the development of new direct acting antiviral agents such as the protease inhibitors boceprevir and telaprevir are long-awaited and their implementation to clinical practice in the near future have the potential for a new standard of care for the treatment of chronic hepatitis C [28]. Although these new antiviral agents showed superior cure rates compared to the current standard of care the public health impact of these new and better medications will remain limited unless more patients are diagnosed and treatment is initiated [29,30]. To control chronic hepatitis C an increase in treatment uptake is crucial especially in the population of (former) IDUs as these patients have by far the highest prevalence of hepatitis $\mathrm{C}$. On the other hand barriers to HCV-related care are most likely in this "hard to reach" population. An easy to access antiviral treatment linked to OMT has the potential to optimize treatment and cure rates in this "hard to reach" population. We provided a successful example of a low-threshold $\mathrm{HCV}$-related care in a Swiss primary care setting.

\section{Conclusions}

We conclude that a high rate of $\mathrm{CHC}$ eradication in unselected patients on OMT is feasible in a primary care setting in Switzerland. The independent association between OMT duration and treatment initiation highlights the important role of opioid substitution as a therapeutic framework to optimize $\mathrm{CHC}$ care in a patient group that significantly contributes to the global burden of liver diseases caused by HCV infection.

\section{Abbreviations}

CHC: Chronic hepatitis C; IDU: Injection drug user; GP: General practitioner; SVR: Sustained virological response; OMT: Opioid maintenance treatment; pegIFN: Pegylated interferon.

\section{Competing interest}

The authors declare that they have no competing interest.

\section{Authors' contributions}

Drs. Seidenberg, Rosemann and Senn designed the study. Dr. Seidenberg collected data and was responsible physician for the opioid maintenance program and the hepatitis C treatment. Drs. Senn and Seidenberg managed the literature searches and summaries of previous related works. Dr. Senn undertook the statistical analysis and wrote the first draft of the manuscript which was revised and edited by all authors. All authors contributed to and approved the final manuscript.

\section{Author details}

'Institute of General Practice and Health Services Research, University of Zurich, Zurich, Switzerland. ${ }^{2}$ General Private Practice, Zurich, Switzerland.

Received: 10 May 2012 Accepted: 21 December 2012

Published: 8 January 2013

\section{References}

1. Mathei C, Buntinx F, van Damme P: Seroprevalence of hepatitis C markers among intravenous drug users in western european countries: a systematic review. J Viral Hepat 2002, 9:157-173.
2. Verna EC, Brown RS Jr: Hepatitis C virus and liver transplantation. Clin Liver Dis 2006, 10:919-940.

3. Manns MP, McHutchison JG, Gordon SC, et al: Peginterferon alfa-2b plus ribavirin compared with interferon alfa- $2 \mathrm{~b}$ plus ribavirin for initial treatment of chronic hepatitis C: a randomised trial. Lancet 2001, 358:958-965.

4. Fried MW, Shiffman ML, Reddy KR, et al: Peginterferon alfa-2a plus ribavirin for chronic hepatitis C virus infection. N Engl J Med 2002, 347:975-982.

5. Hadziyannis SJ, Sette H Jr, Morgan TR, et al: Peginterferon-alpha2a and ribavirin combination therapy in chronic hepatitis $\mathrm{C}$ : a randomized study of treatment duration and ribavirin dose. Ann Intern Med 2004, 140:346-355.

6. Narasimhan G, Sargios TN, Kalakuntla R, et al: Treatment rates in patients with chronic hepatitis C after liver biopsy. J Viral Hepat 2006, 13:783-786.

7. Morrill JA, Shrestha M, Grant RW: Barriers to the treatment of hepatitis C. Patient, provider, and system factors. J Gen Intern Med 2005, 20:754-758.

8. Falck-Ytter $Y$, Kale $H$, Mullen KD, et al: Surprisingly small effect of antiviral treatment in patients with hepatitis C. Ann Intern Med 2002, 136:288-292.

9. Zanini B, Covolo L, Donato F, et al: Effectiveness and tolerability of combination treatment of chronic hepatitis $\mathrm{C}$ in illicit drug users: metaanalysis of prospective studies. Clin Ther 2010, 32:2139-2159.

10. Bonkovsky HL, Tice AD, Yapp RG, et al: Efficacy and safety of peginterferon alfa-2a/ribavirin in methadone maintenance patients: randomized comparison of direct observed therapy and self-administration. Am J Gastroenterol 2008, 103:2757-2765.

11. Fried R, Monnat M, Seidenberg A, et al: Swiss multicenter study evaluating the efficacy, feasibility and safety of peginterferon-alfa-2a and ribavirin in patients with chronic hepatitis $C$ in official opiate substitution programs. Digestion 2008, 78:123-130.

12. Huber $M$, Weber $R$, Oppliger $R$, et al: Interferon alpha-2a plus ribavirin $1,000 / 1,200 \mathrm{mg}$ versus interferon alpha-2a plus ribavirin $600 \mathrm{mg}$ for chronic hepatitis $C$ infection in patients on opiate maintenance treatment: an open-label randomized multicenter trial. Infection 2005, 33:25-29.

13. Mauss S, Berger F, Goelz J, et al: A prospective controlled study of interferon-based therapy of chronic hepatitis $\mathrm{C}$ in patients on methadone maintenance. Hepatology 2004, 40:120-124.

14. National Institutes of Health Consensus Development Conference Statement: Management of hepatitis C: 2002-June 10-12, 2002. Hepatology 2002, 36:S3-S20.

15. Stoove MA, Gifford SM, Dore GJ: The impact of injecting drug use status on hepatitis C-related referral and treatment. Drug Alcohol Depend 2005, 77:81-86.

16. Marsch LA: The efficacy of methadone maintenance interventions in reducing illicit opiate use, HIV risk behavior and criminality: a meta-analysis. Addiction 1998, 93:515-532.

17. MacGowan RJ, Brackbill RM, Rugg DL, et al: Sex, drugs and HIV counseling and testing: a prospective study of behavior-change among methadonemaintenance clients in New England. AIDS 1997, 11:229-235.

18. Roux P, Carrieri MP, Villes V, et al: The impact of methadone or buprenorphine treatment and ongoing injection on highly active antiretroviral therapy (HAART) adherence: evidence from the MANIF2000 cohort study. Addiction 2008, 103:1828-1836.

19. Senn O, Seidenberg A, Rosemann T: Determinants of successful chronic hepatitis $\mathrm{C}$ case finding among patients receiving opioid maintenance treatment in a primary care setting. Addiction 2009, 104:2033-2038.

20. Seidenberg A, Peng M, Custer R: Prinzipien der sicheren opioidverordnung. Bern: Bundesamt für Gesundheit; 2002.

21. Donovan DM, Bigelow GE, Brigham GS, et al: Primary outcome indices in illicit drug dependence treatment research: systematic approach to selection and measurement of drug use end-points in clinical trials. Addiction 2012, 107:694-708.

22. Irving WL, Smith $\mathrm{S}$, Cater R, et al: Clinical pathways for patients with newly diagnosed hepatitis C - what actually happens. J Viral Hepat 2006, 13:264-271.

23. Butt AA, Justice AC, Skanderson M, et al: Rate and predictors of treatment prescription for hepatitis C. Gut 2007, 56:385-389.

24. Hansen N, Obel N, Christensen PB, et al: Predictors of antiviral treatment initiation in hepatitis C virus-infected patients: a Danish cohort study. J Viral Hepat 2009, 16:659-665. 
25. Prasad L, Spicher VM, Zwahlen M, et al: Cohort Profile: the Swiss Hepatitis C Cohort Study (SCCS). Int J Epidemiol 2007, 36:731-737.

26. Evon DM, Simpson K, Kixmiller S, et al: A randomized controlled trial of an integrated care intervention to increase eligibility for chronic hepatitis $C$ treatment. Am J Gastroenterol 2011, 106:1777-1786.

27. Pelet $A$, Doll $S$, Huissoud $T$, et al: Methadone maintenance treatment in the Swiss Canton of Vaud: demographic and clinical data on 1,782 ambulatory patients. Eur Addict Res 2005, 11:99-106.

28. Hofmann WP, Zeuzem S: A new standard of care for the treatment of chronic HCV infection. Nat Rev Gastroenterol Hepatol 2011, 8:257-264.

29. Thomas DL: Curing hepatitis $C$ with pills: a step toward global control. Lancet 2010, 376:1441-1442.

30. Volk ML, Tocco R, Saini S, et al: Public health impact of antiviral therapy for hepatitis C in the United States. Hepatology 2009, 50:1750-1755.

doi:10.1186/1471-2334-13-9

Cite this article as: Seidenberg et al:: Patients receiving opioid

maintenance treatment in primary care: successful chronic hepatitis $C$ care in a real world setting. BMC Infectious Diseases 2013 13:9.

\section{Submit your next manuscript to BioMed Central and take full advantage of:}

- Convenient online submission

- Thorough peer review

- No space constraints or color figure charges

- Immediate publication on acceptance

- Inclusion in PubMed, CAS, Scopus and Google Scholar

- Research which is freely available for redistribution 